\title{
Quantification of Productivity Changes Due to Work Schedule Changes in Construction Projects. A Case Study
}

Cuantificación de Cambios de Productividad debidos a cambios en las Jornadas Laborales en Proyectos

de Construcción. Un Estudio de Caso

\author{
Ricardo E. Arriagada \\ Pontificia Universidad Católica de Chile \\ Faculty of Engineering \\ rarriaga@ing.puc.cl \\ Casilla 306, correo 22, Santiago de Chile.
}

\author{
Luis F. Alarcón C. \\ Pontificia Universidad Católica de Chile \\ Faculty of Engineering \\ lalarcon@ing.puc.cl \\ Casilla 306, correo 22, Santiago de Chile. \\ Código: 0207 \\ Fecha de Recepción: 01.01.2014. \\ Fecha de Aceptación: 01.04.2014.
}

Abstract

In a copper-molybdenum open pit mine in Chile, a collective labor dispute in April 2012 halted work on the site; the main problem was the negotiation of unified work schedules for contractors, subcontractors and their own staff. To avoid conflicts that could delay this project, the parties agreed to submit to arbitration by an external agency, to determine and quantify the existence of lost productivity caused by the change of work schedules. The external agency considered three basic elements: a) the temporal dimension to allow the comparison of two work schedules, b) the acceptable range of productivity losses associated with these schedules; and c) an unbiased mechanism to allocate a productivity loss within the range associated with each schedule. This paper presents the analysis of productivity loss when work schedules are extended, the method utilized, and the results obtained. This probabilistic model randomly assigns discrete values of productivity loss for each day of the work schedules, and uses inefficiency ranges from industry research; this allows a non-biased, easy to implement, comparison of work schedules.

Keywords: Probabilistic model, working day extended, productivity loss, mining project, case study.

\section{INTRODUCTION}

Chile is ranked as one of the leading producers of copper in the world, and has the largest reserves of copper, gold, molybdenum, silver potassium and other minerals. Mining in Chile represent $15.2 \%$ of the GDP, and is the country's major economic activity (De Solminihac, 2012).

The sustained growth of the Chilean mining sector has expanded into higher areas in the mountain range of Los Andes (Cordillera de Los Andes), an area with approximately $80 \%$ of the mining operations that are located in territories over 3,000 m.a.s.l., and are far away from urban areas (Carrasco and Vega, 2011).

Mining companies, as well as their contractors and subcontractors, have chosen to build their camps close to the mining site, and they use exceptional work schedules to ensure productivity while providing sufficient recovery time for their personnel. The local legal guidelines acknowledge two types of unique work schedules, as described by the hours per day of a daily work shift and the number of working days versus days off. There are 1:1 shifts, with a maximum workday of 12 hours per day; 1.3:1 shifts, with a maximum workday of 12 hours per day, and 2:1 shifts, with a maximum workday of 9.6 hours per day.

\section{PROBLEM IDENTIFICATION}

In 2010, an important Japanese consortium designed and began construction on a copper-molybdenum open pit mining project in the Atacama Chile region, at an altitude of 3,850 m.a.s.l. The project has recently completed the construction phase, employing more than five thousand workers at the mining site, including personnel from contractors, subcontractors and direct hires. In April 2012, a conflict with a group of laborers halted the mining site; the main problem cited was the negotiation of a unified work schedule, given the large variety of unique work schedules among the contractor and subcontractor personnel. The unique work schedule used mainly by the contractors' personnel was $14 \times 7 \times 9,6$ : specifically 14 workdays of 9.6 hours/day and 7 days off. The other work schedule, used less often by personnel from contractors and subcontractors, was 10x10x11: specifically 10 work days with a daily 11 hour shift, and 10 days off.

In negotiations with the union labor, they agreed upon an unique work schedule of $10 \times 10 \times 11$ for all workers at the mining site, in addition to other improvements. Contractors who used to have $14 \times 7 \times 9.6$ shifts asked management to acknowledge the monthly production time difference per worker; in accordance with the new legal guidelines, the $14 \times 7 \times 9.6$ work schedule equates to 192 direct-worker-hours-per-month and the $10 \times 10 \times 11$ shift equals 165 direct-worker-hours-per-month. 
Management recognized the direct manpower loss created by this change in work schedules, recognizing the 27 directworker-hours-per month, but they didn't acknowledge the presumed productivity loss, since in their opinion, the increase in the daily shift increased the direct production time.

Given this discrepancy, and so as to not generate any more conflicts that could impact the mine's work schedule, the parties agreed to arbitration from a qualified external party, who would clearly and consistently determine if there was or wasn't a productivity loss due to the work schedule change, and the external party would also quantify that difference. This document will determine if there are productivity changes when a $14 \times 7 \times 9.6$ work schedule replaces a $10 \times 10 \times 11$ work schedule, and we will also calculate the magnitude of this change.

\section{BACKGROUND}

Productivity studies in the construction sector have been debated over time due to their scope and complexity. Key factors which affect labor productivity in the construction and assembly sectors have been identified in papers by Oglesby et.al. (1989), Borcherding \& Alarcón (1991), Sanders \& Thomas (1991), Thomas (1992), Langford et.al. (1995), Motwani et.al. (1995), Lim \& Alum (1995), Baba (1995); Zakeri et.al. (1996), Lema (1995), Kaming et.al. (1997), Olomolaiye et.al. (1998), Thomas et.al. (1999), Makulsawatudom \& Emsley (2002), Ibbs (2005), Hanna et.al. (2005), Nepal et.al. (2006), Khoramshahi et.al. (2006), Enshassi et.al. (2007), Alinaitwe et.al. (2007), Weng-Tat (2007), Hanna et.al. (2008); y Kazaz et.al. (2008).

In addition to identifying key factors, there was also a need to group them into categories. Borcherding \& Alarcón (1991) identified 50 factors and classified them into 8 categories; Rojas \& Aramvareekul (2003) identified 18 factors that affect labor productivity and classified them into 4 categories; Liberda et.al. (2003) identified 51 factors and classified them into 3 categories; Soekiman et.al. (2011) identified 113 factors affecting productivity and grouped them into 15 categories.

In order to organize the different factors that affect of productivity loss in a simple format, we highlight six main factors, namely: organizational, motivational, operational, climate, cognitive and physiological. We will assume a work crew doing a specific type of work on the same project, with the same supervision, with the same members and designation of the internal roles, with the same salary and benefits, with the same organization of daily work, and working in the same field conditions; the only difference is the type of work schedule. We can assume that other factors - organizational, motivational, operational, cognitive and climate - have the same influence on both schedules, so we don't observe any significant changes when analyzing these variables for the given work schedules. The only category we are analyzing is the physiological variable.

\section{Analysis of physiological factors}

The main physiological factors affecting labor productivity are: physical fatigue, created by long work shifts; mental fatigue, created by jobs with a high level of complexity; fatigue due to stress, created by highly contaminated work environments; and boredom, created by non-demanding tasks which are excessively repetitive. In the case of the miners, and considering the same crew of workers who do the same job, the only physiological factor that should be considered is physical fatigue.

\section{Daily and weekly fatigue}

Generally, demanding physical work can cause fatigue during a work shift, and should be followed by a rest period to allow the body to recover. Research in the industry has found that other situations, that were not directly related to heightened consumption of energy, also affected productivity in a part-time shift as well as in a morning versus an afternoon shift.

Figure 1 shows that during a shift of an 8 hour day, peak productivity is found near 11:00. and the peak afternoon productivity is between $13: 00$ and 14:00. On the other hand, productivity also varies with the day of the week.
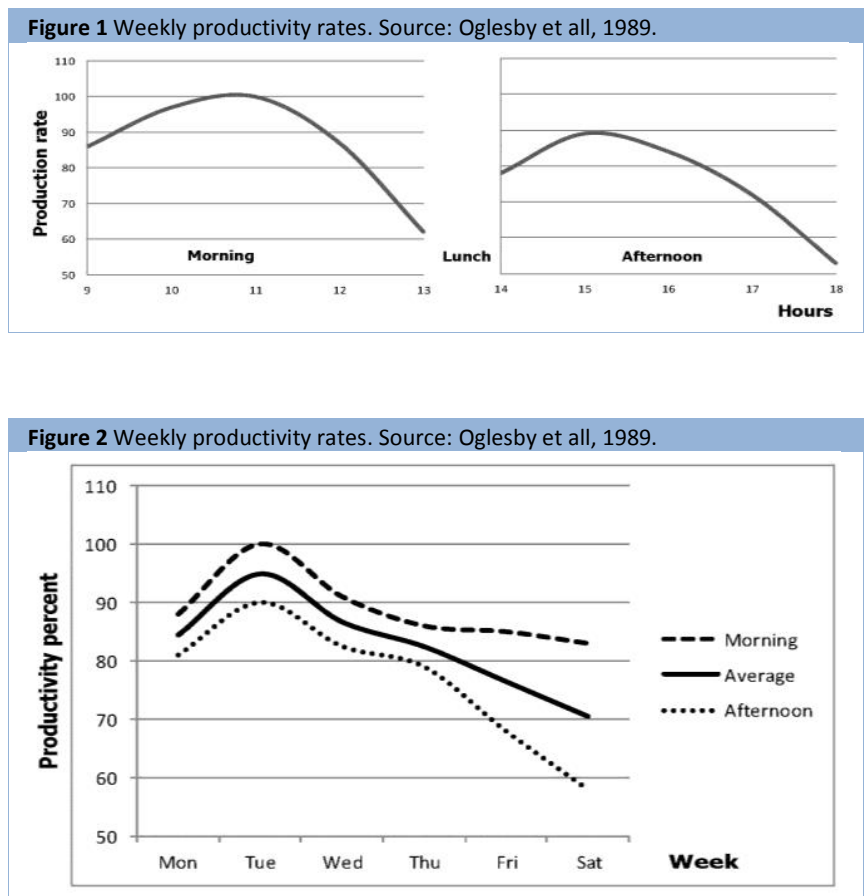

Figure 2 shows the productivity graph indicating morning, afternoon and average productivity for an 8 hour daily shift. The peak productivity of the week is found on Tuesday, at approximately 11:00; the lowest productivity is on Saturday at 18:00 hours.

It is worthy to note that productivity varies a lot throughout the day and the week, so the values included in the productivity charts and graphs indicate average values.

\section{Fatigue in extended work shifts with overtime}

Both the $14 \times 7 \times 9.6$ shift and the $10 \times 10 \times 11$ shift are shifts with paid overtime. The $14 \times 7 \times 9.6$ shift contemplates spending 9.6 hours per day at the worksite, for fourteen days straight; the $10 \times 10 \times 11$ shift requires staying on the job for 11 hours per day, for ten straight days. In the case of both schedules, the time 
spent on the job is counted from the arrival of the worker at the worksite, up until the worker leaves to return to the mining camp. They also both include one hour of lunch at the worksite during the daily shift.

There are multiple studies which analyze productivity loss due to extended work schedules and continuous working days over five days per week. One of the most well-known is the National Electrical Contractors Association (NECA study, which is also referred to as the Mechanical Contractors Association of America or MCAA), and another by Oglesby et.al. (1989). Even though these are earlier publications, these studies are broadly referenced by more current authors who study this topic, such as Mubarak (2010); Schwartzkopf, (2004 y 2008); Hanna \& Haddad (2009); Dozzi \& AbouRizk (2011) and Thomas (2012).

\section{PROPOSED APPROACH TO THIS PROBLEM}

Using the worksite's control activities which collect and register important data regarding the worksite's progress, it is possible to account for daily production units, as well as daily attendance of the personnel. The quality of the data registries and the appropriate breakouts of data will allow us to determine the daily productivity of a work team at a specific worksite. We can then add the daily events related to productivity that are registered in the worksite's log, such as daily fluctuations in the movement of materials, equipment and information; climate changes, etc. This would provide the ability to adjust and normalize productivity of the work shifts so as to be able to compare them.

In practice, the quantity and quality of data collected daily from the worksite are not sufficient to do a robust analysis of productivity for a specific worksite; the worksite log also may not be precise, since the individuals in charge may only be interested in registering events that could have an impact on their own productivity or that of third parties. The lack of data reflects the basic rule which states that the value of the information must cover the cost of its collection.

Therefore, it is impossible to use the empirical data from the worksite's tracking log to support a comparative analysis of productivity loss of two work schedules due to physical fatigue, so another simple yet rigorous method was chosen; this method, together with available research, allows us to get past the limitations that were stated earlier. We determined that this method should consider three major elements. The first is the dimension of time, to be able to compare these two work schedules; the second is the acceptable range of productivity losses associated with the schedules; and third, a non-biased mechanism that assigns productivity within a range associated with each schedule.

\section{Time Dimension}

To compare these two work schedules, the time lapsed is critical, since a 9.6 hour shift, done over 14 days straight, and ending that cycle with 7 days of continuous rest, cannot be directly compared with a different schedule of 11 hours/day, for 10 consecutive days, and ending that cycle with 10 days of rest. In both schedules, the direct production time is completely different, as are the effects of fatigue and the recuperating effect of the rest periods.

When we graph these two schedules simultaneously, the two shifts start on day 1 . They are only comparable starting on day 57 , through day 60 (see appendix). During this period, the $14 \times 7$ shift will have had three work periods, two rest periods and will be entering their first day of rest for the third 7 day period. On the other hand, the $10 \times 10$ shift will have had three work periods, two rest periods and will be on day 7 of a 10 day rest period.

Therefore, in this case, the comparative analysis of the two work schedules must be done every two months, which is when we can obtain the comparable monthly productivity losses. Productivity losses are expressed in cost per work hours per person assuming that the workers are paid on a monthly basis.

\section{Productivity Loss Ranges}

After analyzing the graphs and tables which quantify the productivity losses, referred to as inefficiencies, we choose to use table 9-2 from Oglesby et.al. (1989), given that it is based on Figure 2 (Tabulated Results of the NECA's Southeastern Michigan Study, 1989), which provides the range of inefficiencies for each scenario. The table is shown below, with the necessary adjustments for the $14 \times 7 \times 9.6$ and the $10 \times 10 \times 11$ schedules.

As seen in Table 1, interpolation allowed us to generate a range of inefficiencies for the 10 day work schedule with 11 hour daily shifts (between $21 \%$ and $23 \%$ ), and an inefficiencies range for the other schedule with 14 days of 9.6 hour/day shifts (between $19 \%$ and $22 \%$ ). Since a range of inefficiencies is indicated for both work schedules, the inefficiency can be any discrete number in this range. So, for the $14 \times 7$ work schedule, the values may be 19, 20, 21 and 22; for the 10x10 work schedule : 21,22 and23. Both ranges share inefficiencies 21 and 22.

\section{Assigning Productivity Loss}

Table 1 shows the range of possible inefficiency values, for both the $14 \times 7$ schedule with 9.6 hours/day as well as the $10 \times 10$ schedule with 11 hour/day shifts. The use of either the values from either of these ranges for the inefficiency calculation should have a rationale, which we do not have. Given this restriction, a probabilistic model which randomly assigns a daily productivity loss for each work schedule provides the best approximation to the actual situation, since the model assigns an arbitrary inefficiency value to each day, taken from their respective ranges, without human intervention and therefore without the need for a rationale. Biases are eliminated by assigning equal probability of occurrence to all of the values in the ranges that are used for either work schedule. 
In the appendix of this paper, a probability model is presented which was developed and run in Excel using the add-in @Risk. The model uses a simulation and 10,000 iterations. A summary of the results is presented in Table 2.

Table 2 shows average efficiency (100 - non-efficiency) for the $14 \times 7$ work schedule, this assigns 42 work day values randomly chosen from a 57-60 day work schedule. Likewise, the average efficiency for the $10 \times 10$ work schedule is calculated; it has 30 work day values, from the same 57-60 day period. Each of the efficiency averages is applied to the amount of nominal hours for each schedule, so as to obtain hours at $100 \%$ efficiency for each work schedule. The effective loss of productivity when changing the $14 \times 7$ work schedule to the $10 \times 10$ schedule is 61.41 hours; from that number, we subtract 54 hours of recognized loss of manpower, for the two month period analyzed, resulting in 7.41 hours of actual productivity loss for the two month period. According to this, the productivity loss for the work schedule change, not yet accounted for to date, is $2.32 \%$ per month. Given the model assigns inefficiencies from the random selection of discrete values for the range of possible inefficiencies for both work schedules, a sensibility analysis will let us observe the maximum possible range of comparable inefficiencies as well as the inefficiency within this range which can be randomly assigned by the model.

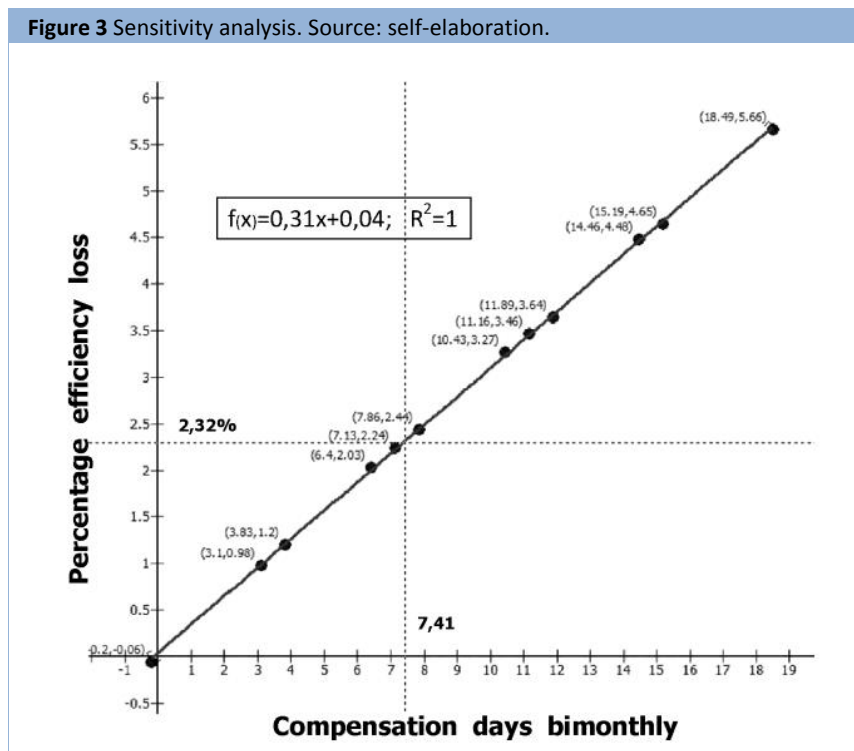

According to table 1 , the minimum value of a range of inefficiencies, when comparing the two work schedules, is the maximum inefficiency for each of the 42 days in the $14 \times 7 \times 9.6$ work schedule (22\%), and the minimum inefficiency for each of the 30 days of the $10 \times 10 \times 11$ work schedule (21\%). The maximum value of the inefficiencies, when comparing these two work schedules, is the minimum efficiency for each of the 42 days of the $14 \times 7 \times 9.6$ work schedule $(19 \%)$, and the maximum inefficiency for each of the 30 days of the $10 \times 10 \times 11$ work schedule (23\%). Figure 3 presents this analysis, including the values obtained from the model.

Three collinear ranges are shown in Figure 3; this data has already incorporated the acknowledged manpower losses.

The first range is $0.2,-0.06-3.10,0.98$ which represents the comparative values where the $10 \times 10 \times 11$ work schedule is more efficient than the $14 \times 7 \times 9.6$ work schedule. The second is the $3.10,0.98$ - 3.83,1.20 range representing the comparative values of equal efficiency for either of the work schedules. And the third range of $3.83,1.20-18.49,5.66$ represents the comparative values where the $14 \times 7 \times 9.6$ schedule is more efficient than the $10 \times 10 \times 11$ schedule. The value generated by our model $(7.41,2.32)$ is located in the range where the $14 \times 7 \times 9.6$ is more efficient than the $10 \times 10 \times 11$ schedule, located near the $25 \%$ point of this section and above $40 \%$ of the entire range of possible values $(-0.2,-0.06-18.49,5.66)$.

\section{CONCLUSIONS}

In December, 2012, the parties involved in the dispute expressed their complete conformity with the recommendation proposed in this analysis, stating that it was robust, easy to understand and to recreate, and definitely non-biased. We can therefore appreciate the generalization possible with the proposed methodology for cases of comparative analysis of productivities of different work schedules, as well for managing productivity variability for the same work schedule in given periods, for situations or scenarios where reliable information is not available.

\section{REFERENCES}

Alinaitwe HM, Mwakali JA, and Hansson B (2007). Factors Affecting the Productivity of Building Craftsmen-Studies of Uganda. Journal of Civil Engineering and Management, XIII (3), 169176.

Baba K (1995). Cultural Influences on Construction Management. Proceeding of the 1st International Conference on Construction Project Management, pp. 99-106, Singapore.

Borcherding JD, and Alarcón LF (1991). Quantitative Effects on Construction Productivity. The Construction Lawyer, Vol. 11, No. 1, pp. 36-48, January 1991.

Carrasco, C. y Vega, P. (2011). Una aproximación a las condiciones de trabajo en la gran minería de altura. Cuaderno de Investigación N0. Ministerio del Trabajo de la República de Chile.

De Solminihac, H. (2012). Chile país minero: Una oportunidad laboral. Primer encuentro de alternativas para la minería, abril 2012. Ministerio de Minería de la República de Chile.

Dozzi SP, and AbouRizk SM (2011). Productivity in Construction. Chapter 3. NRCC-37001.

Enshassi A, Mohamed, S, Mustafa ZA, and Mayer PE (2007). Factors Affecting Labour Productivity in Building Projects in the Gaza Strip. Journal of Civil Engineering and Management, XIII (4), 245-254. 
Hanna AS, Taylor CS, and Sullivan KT (2005). Impact of Extended Overtime on Construction Labor Productivity. Journal of Construction Engineering and Management, 131(6), pp. 734739.

Hanna AS, Chang CK, Sullivan KT, and Lackney JA (2008). Impact of Shift Work on Labor Productivity for Labor Intensive Contractor. Journal of Construction Engineering and Management, 134(3), pp. 197-204.

Hanna AS, and Haddad G. (2009). Overtime and Productivity in Electrical Construction. ASCE. Construction Research Congress, Wisconsin-Madison.

Ibbs W (2005). Impact of Change's Timing on Labor Productivity. Journal of Construction Engineering and Management, 131(11), pp. 1219-1223.

Kaming PF, Olomolaiye P, Holt GD, and Harris FC (1997). Factors Influencing Craftmen's Productivity in Indonesia. International Journal of Project Management, 15(1), p. 2130.

Kazaz A, Manisali E, and Ulubeyli S (2008). Effect of Basic Motivational Factors on Construction Workforce Productivity in Turkey. Journal of Civil Engineering and Management, 14(2), pp. 95106.

Khoramshahi F, Dehghan R, and Mortaheb MM (2006). Factors Influencing Construction Productivity. Proceedings of the 10th EASEC, Bangkok, Thailand.

Langford D, Hancock MR, Fellows R, and Gale AW (1995). Human Resources Management in Construction. Longman Scientific \& Technical.

Lema NM (1995). Construction of labour productivity modeling. University of Dar Elsalaam.

Lim EC and Alum J (1995). Construction Productivity: issues encountered by contractors in Singapore. International Journal of Project Management, 13(1), p. 51-58.

Makulsawatudom and Emsley (2002). Critical factors influencing construction productivity in Thailand. Proceeding of CIB 10th International Symposium Construction Innovation and Global Competitiveness, Cincinnati, Ohio, USA.

Liberda, M., Ruwanpura, J., and Jergeas, G. (2003). "Construction productivity improvement: A study of human, management and external factors". Proceedings of the American Society for Civil Engineers, Construction Research Congress, Honolulu, Hawaii, USA.

MCAA (1987). Management Methods Committee Bulletin . Mechanical Contractors Association of America.

Motwani J, Kumar A, and Novakoski M (1995). Measuring Construction Productivity: a Practical Approach. Work Study, 44(8), pp. 18-20.
Mubarak S. (2010). Construction Project Scheduling and Control, Second Edition. Chapter 8. John Wiley \& Sons: Hoboken, New Jersey.

NECA (1989). Overtime and Productivity in Electrical Construction, Second Edition. National Electrical Contractors Associations, Washington.

Nepal MP, Park M, and Son B (2006). Effects of Schedule Pressure on Construction Performance. Journal of Construction Engineering and Management, 132(2), pp. 182-188

Oglesby CH, Parker HW, and Howell GA (1989). Productivity Improvement in Construction. McGraw-Hill: New York.

Olomolaiye P, Jayawardane A, and Harris F (1998). Construction Productivity Management. Chartered Institute of Building, UK.

Rojas, M., and Aramvareekul, P. 2003. Labor productivity drivers and opportunities in the construction industry. J. Manage. Eng., $192,78-82$.

Sanders SR and Thomas HR (1991). Factors Affecting Masonry-Labor Productivity. Journal of Construction Engineering and Management, 117(4), pp. 626-644.

Soekiman A, Pribadi KS, Soemardi BW, and Wirahadikusumah RD (2011). Factors Relating to Labor Productivity Affecting the Project Schedule Performance in Indonesia. Procedia Engineering 14 (2011) 865-873.

Schwartzkopf W. (2004). Calculating Lost Labor Productivity in Construction Claims. Second Edition. Aspen Publishers: New York.

Schwartzkopf W. (2008). Calculating Lost Labor Productivity in Construction Claims. Cummulative Supplement. Second Edition. Aspen Publishers: New York.

Thomas HR (1992). Effects of Schedule Overtime on Labor Productivity. Journal of Construction Engineering and Management, 118(1), pp. 60-76.

Thomas HR, Riley DR, and Sanvido VE (1999). Loss of Labor Productivity due to Delivery Methods and Weather. Journal of Construction Engineering and Management, 125(1), pp. 3946.

Thomas HR (2012). Benchmarking Construction Labor Productivity. Journal of Construction Engineering and Management,. SC.1943-5576.0000141. Accepted Manuscript.

Weng-Tat C (2007). A Systems Perspective of Construction Productivity Improvement Efforts. Proceeding of the $1^{\text {st }}$ International Conference of EACEF, Jakarta-Indonesia.

Zakeri M, Olomolaiye PO, Holt GD, and Harris FC (1997). Factors affecting the motivation of Iranian constructions operatives. Building and Environment 1997; 32: 161-6. 
THE INFLUENCE OF OVERTIME ON EFFIGENCY IN CONSTRUCTION CREWS

\begin{tabular}{|c|c|c|c|c|c|c|c|c|c|c|c|c|}
\hline \multirow{2}{*}{$\begin{array}{c}\text { Week } \\
\text { Days }\end{array}$} & \multirow{2}{*}{$\begin{array}{c}\text { Days } \\
\text { Hrs }\end{array}$} & \multirow{2}{*}{$\begin{array}{c}\text { Week } \\
\text { Hrs }\end{array}$} & \multicolumn{10}{|c|}{ PERCENT INEFFICIENCY } \\
\hline & & & \multicolumn{2}{|c|}{7 days } & \multicolumn{2}{|c|}{10 days } & \multicolumn{2}{|c|}{14 days } & \multicolumn{2}{|c|}{21 days } & \multicolumn{2}{|c|}{28 days } \\
\hline 6 & 9,0 & 54,0 & 4 & 6 & 5 & 7 & 6 & 9 & 8 & 12 & 10 & 15 \\
\hline 6 & 10,0 & 60,0 & 7 & 9 & 9 & 11 & 11 & 14 & 14 & 18 & 18 & 23 \\
\hline 6 & 12,0 & 72,0 & 12 & 14 & 15 & 17 & 18 & 21 & 24 & 28 & 30 & 35 \\
\hline 7 & 8,0 & 56,0 & 9 & 11 & 1 & 13 & 14 & 16 & 18 & 22 & 23 & 27 \\
\hline 7 & 9,0 & 63,0 & 11 & 13 & 14 & 16 & 17 & 20 & 22 & 26 & 28 & 33 \\
\hline 7 & 9,6 & 67,2 & 13 & 15 & 16 & 18 & 19 & 22 & 26 & 30 & 32 & 37 \\
\hline 7 & 10,0 & 70,0 & 14 & 16 & 17 & 19 & 21 & 24 & 28 & 32 & 35 & 40 \\
\hline 7 & 11,0 & 77,0 & 17 & 19 & 21 & 23 & 26 & 29 & 34 & 38 & 43 & 48 \\
\hline 7 & 12,0 & 84,0 & 20 & 22 & 24 & 27 & 30 & 33 & 40 & 44 & 50 & 55 \\
\hline
\end{tabular}

Table 2 Comparative analysis of working days by using a probabilistic model. Source: Self-Elaboration

\begin{tabular}{|c|c|c|c|}
\hline & \multicolumn{2}{|c|}{ WORKING DAYS } & \\
\hline & $14 \times 7$ & $10 \times 10$ & \\
\hline Daily hours & 9,6 & 11 & \\
\hline Productive days in two months & 42 & 30 & \\
\hline \multicolumn{3}{|l|}{ A SIMULATION AND TEN THOUSAND ITERATIONS } & \multirow{2}{*}{ DIFFERENCES } \\
\hline Efficiency average of the work day & $79,26 \%$ & $78,23 \%$ & \\
\hline Productive hours at $100 \%$ efficiency in two months & 319,58 & 258,17 & 61,41 hours \\
\hline \multicolumn{3}{|l|}{ Productivity loss recognized ( 27 hours per month) } & 54 hours \\
\hline \multicolumn{3}{|c|}{ PRODUCTIVITY REMAINING LOSS IN TWO MONTHS } & 7,41 hours \\
\hline
\end{tabular}

Appendix 1 Probabilistic Analysis Comparing $14 \times 7$ and 10x10 Work Schedules. Source: Self-Elaboration

\begin{tabular}{|l|l|l|l|l|l|l|l|l|l|l|l|l|l|l|l|l|l|l|l|l|l|l|l|l|l|l|l|l|l|l|} 
Month 1 & 1 & 2 & 3 & 4 & 5 & 6 & 7 & 8 & 9 & 10 & 11 & 12 & 13 & 14 & 15 & 16 & 17 & 18 & 19 & 20 & 21 & 22 & 23 & 24 & 25 & 26 & 27 & 28 & 29 & 30 \\
\cline { 2 - 13 } & & & &
\end{tabular}

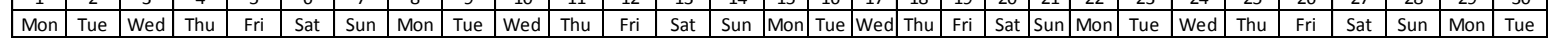

\begin{tabular}{ll|l|l|l|l|l|l|l|l|l|l|l|l|l|l|l|l|l|l|l|l|l|l|l|l|l|l|l|l|l|}
$14 \times 7$ schedule & 80 & 79 & 78 & 78 & 80 & 79 & 80 & 79 & 80 & 78 & 79 & 81 & 79 & 78 & off & off & off & off & off & off & off & 78 & 80 & 78 & 78 & 81 & 80 & 81 & 79 & 79 \\
\hline
\end{tabular}

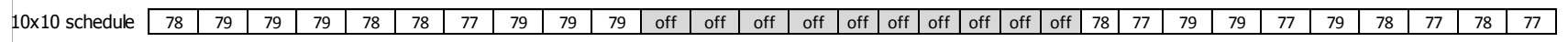

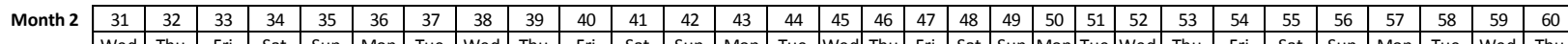

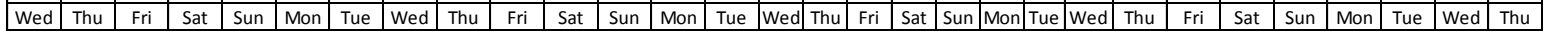

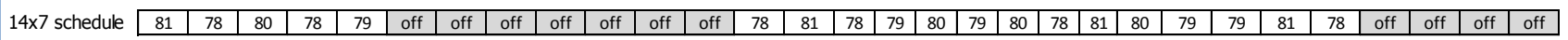

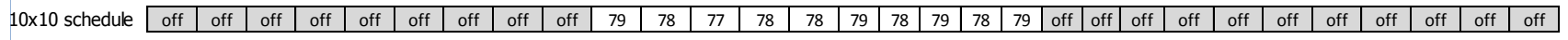

14x7 schedule 79,26 average inefficiency bimonthly $\quad 319,58$ Total hours for the two month period, corrected for inefficiencies, for the $14 \times 7$ schedule

10x10 schedule 78,23 average inefficiency bimonthly 258,17 Total hours for the two month period, corrected for inefficiencies, for the $10 \times 10$ schedule

61,41 Hours of total productivity loss due to change of workday from $14 \times 7$ to $10 \times 10$ for two months of analysis 54,00 Acknowledgement of the manpower loss due to the change in work schedule for the two month period.

7,41 Hours that the supervisor should pay the contractor for a period of two months.

$\mathbf{2 , 3 2} \%$ equation of the monthly productivity loss due to the change in work schedule from 14.7 to $10 \times 10$

\begin{tabular}{|c|c|c|c|c|}
\hline \multirow{4}{*}{$\begin{array}{rr}1 & 1 \\
19 & 20\end{array}$} & 1 & 1 & & \\
\hline & 21 & 22 & & ifficiencies for the $14 \times 7$ work schedule \\
\hline & 1 & 1 & 1 & ability \\
\hline & 21 & 22 & 23 & inefficiencies for the $10 \times 10$ work schec \\
\hline
\end{tabular}


